\title{
Penerapan Game Angry Bird untuk Materi Gerak Parabola pada Pembelajaran fisika
}

\author{
Nira Nurwulandari ${ }^{(1)}$ \\ ${ }^{1}$ Universitas Nahdlatul Ulama Blitar, \\ Email: 1nirra.nrwd@gmail.com \\ DOI: https://doi.org/10.28926/riset_konseptual.v2i4.81
}

\begin{abstract}
ABSTRAK
Penelitian ini bertujuan untuk mendeskripsikan penerapan game Angry Bird untuk materi gerak parabola pada Pembelajaran Fisika Pada Pokok Bahasan Energi. Desain penelitian yang digunakan adalah penelitian mix-method dengan embedded experimental, dengan populasi seluruh siswa SMA kelas X semester ganjil angkatan 2018/2019. Sampel penelitian adalah kelas X IPA 1 yang diambil dengan teknik Cluster Random Sampling. Berdasarkan hasil analisis uji-t berpasangan diperoleh kesimpulan bahwa terdapat perbedaan yang signifikan antara hasil belajar kognitif fisika siswa sebelum dan setelah pembelajaran.
\end{abstract}

Kata kunci: game, angry bird, gerak parabola, fisika

\section{PENDAHULUAN}

Pembelajaran Fisika merupakan salah satu pelajaran yang paling dihindari oleh Siswa. Bahkan Fisika merupakan pelajaran yang paling sulit diantara pelajaran yang lainnya, sehingga banyak Siswayang kurang bersemangat dalam belajar. Keadaan ini sungguh ironis mengingat ilmu fisika adalah salah satu ilmu yang harus dikuasai bagi mereka yang ingin melanjutkan ke Perguruan Tinggi terutama pada jurusan MIPA (Matematika dan Ilmu Pengetahuan Alam). Kondisi yang sama juga dialami para Siswa di SMA Blitar. Pembelajaran fisika kurang menarik perhatian Siswa sehingga mereka kurang fokus dalam mengikuti kegiatan belajar mengajar. Melihat kondisi tersebut saya sebagai pendidik berinisiatif untuk membuat pelajaran yang menarik sehingga dapat meningkatkan motivasi siswa dalam belajar fisika.

Motivasi siswa sangat penting dalam pembelajaran fisika. Game adalah salah satu media pembelajaran yang dapat digunakan untuk meningkatkan motivasi. Faktanya, game disenangi oleh semua siswa. Salah satu contoh game yang sangat terkenal di kalangan siswa adalah Angry Bird. Banyak orang yang mengetahui bahkan sering memainkan Angry Bird di gadgetnya masing-masing, biasanya di tablet atau smarthphone. Cara memainkan Angry Bird adalah menembakkan burung dengan ketapel menuju sasaran yang berupa babi (IGN, 2009).

Tantangan dalam pembelajaran menggunakan game Angry Bird adalah harus mengubah konsep dalam game menjadi serangkaian kegiatan pembelajaran. Kegiatan pembelajaran menggunakan game Angry Bird tidak hanya untuk bersenang-senang tetapi yang juga sangat penting adalah konsep fisika tersampaikan dengan baik. Dengan memanfaatkan game Angry Bird diharapkan Siswa lebih bersemangat dalam mempelajari fisika dan tentunya konsep fisika lebih mudah dipahami oleh siswa.

Pembelajaran menggunakan game Angry Bird cocok diterapkan pada materi gerak parabola. Penggunaan game Angry Bird pada pembelajaran fisika diharapkan siswa dapat memahami konsep tentang gerak parabola (Allain, 2011). Materi gerak parabola merupakan materi yang cukup sulit diterapkan pada mata pelajaran fisika, sehingga perlu visualisasi menggunakan media pembelajaran. Game angry bird dirancang untuk menjelaskan beberapa konsep tentang gerak parabola, seperti pengaruh sudut lontar terhadap jarak benda dan ketinggian. Pengaruh kecepatan awal terhadap jarak tempuh dan waktu. Pada saat melakukan pembelajaran menggunakan game Angry bird, Peserta didik tetap diminta untuk menentukan sudut lontar dan waktu tempuh, sehingga esensi dari kegiatan pembelajaran tetap dilakukan. 
Vol. 2 No. 4, Oktober 2018;

Berdasarkan uraian tersebut, maka penting untuk dilakukan penelitian game Angry bird terhadap hasil belajar kognitif fisika siswa pada materi gerak parabola. Penelitian ini berusaha meningkatkan hasil belajar kognitif tentang bagaimana dampak penggunaan game Angry bird terhadap hasil belajar kognitif fisika siswa. Oleh karena itu, perlu dilakukan penelitian dengan judul penerapan game Angry bird untuk materi gerak parabola terhadap pembelajaran fisika.

\section{METODE}

Penelitian ini merupakan penelitian mixed method dengan populasi penelitian yaitu seluruh siswa SMA kelas X semester ganjil angkatan 2018/2019 SMA Mamba'us Sholihin Blitar. Sampel penelitian ini adalah siswa X IPA 2 yang diambil dengan teknik Cluster Random Sampling. Teknik cluster random sampling adalah teknik pengambilan sampel dengan cara mengundi dari dua kelas X IPA. Berdasarkan populasi yang terdiri dari 2 kelas diambil 1 kelas secara acak sebagai sampel. Sampel yang diperoleh adalah kelas X IPA2 sebagai sampel penelitian.

Jenis penelitian ini adalah penelitian mixed method dengan embedded experimental. Data yang dikumpulkan terdiri atas data kuantitatif dan data kualitatif. Berikut rancangan penelitian dari Creswell (2007: 68).

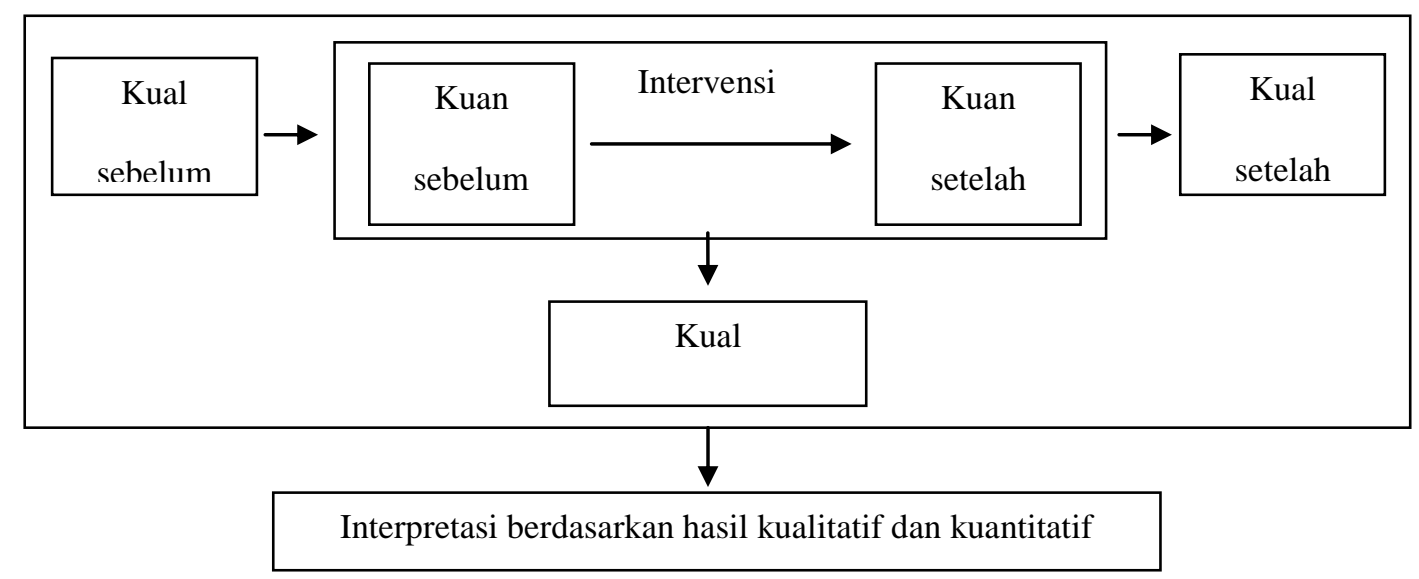

Penelitian diawali dengan pre-test untuk mengetahui hasil belajar kognitif dengan menggunakan tes kognitif fisika siswa dan dilanjutkan wawancara. Kemudian dilaksanakan intervensi dengan penerapan game Angry Bird. Intervensi dilaksanakan selama 4 pertemuan. Selama intervensi dilakukan, siswa akan diminta mengisi LKS dan menjawab soal kuis tentang konsep gerak parabola pada setiap pertemuan. Selain itu, keterlaksanaan RPP diamati oleh ebserver dan kegiatan pembelajaran didokumentasikan dengan foto. Setelah intervensi diterapkan, siswa mengikuti posttest untuk mengetahui hasil belajar kognitif fisika siswa dengan menggunakan statistic tes kognitif dan dilanjutkan wawancara. Hasil interpretasi data akan menjadi dasar dalam penarikan kesimpulan sesuai dengan rumusan masalah penelitian.

Data pre-test dan pos-test hasil belajar kognitif dianalisis dengan menggunakan analisis data kuantitaif. Data ini dianalisis untuk mengetahui perubahan hasil belajar kognitif siswa pada pre pre-test dan pos-test. Statistik yang digunakan adalah statistic deskriptif dan statistic inferensial. Statistik deskriptif menggunakan program SPSS dimasksudkan untuk mengetahui skor tertinggi (maksimum), skor terendah (minimum), dan skor rata-rata (mean) hasil belajar kognitif siswa. Selanjutnya inferensial menggunakan program SPSS dimaksudkan untuk mengetahui apakah terdapat perbedaan yang signifikan antara skor hasil belajar kognitif siswa pada pretest dan pos-test dengan menggunakan uji-t berpasangan. Selain itu, data ini dianalisis untuk mengetahui perubahan hasil belajar kognitif siswa pada pre-test dan pos-test. 
Vol. 2 No. 4, Oktober 2018;

HASIL

Pada umumnya siswa telah belajar konsep fisika yang berhubungan dengan gerak parabola. Walaupun demikian masih ada siswa yang tidak memahami konsep fisika. Siswa tidak memahami konsep fisika dapat dilihat dari jawaban siswa ketika diberi masalah saat pembelajaran. Tabel-tabel berikut mendeskripsikan distribusi jawaban siswa tentang hasil belajar kognitif fisika dengan game Angry Bird yang berhubungan dengan gerak parabola.

Tabel 1. Deskripsi Jawaban LKS pada Materi Gerak Prabola

\begin{tabular}{|c|c|c|c|}
\hline No. & Subtopik & $\begin{array}{l}\text { Persentase } \\
\text { jawaban (\%) } \\
\text { hasil belajar } \\
\text { kognitif }\end{array}$ & Contoh Pernyataan \\
\hline 1 & $\begin{array}{l}\text { Menentukan } \\
\text { sudut } \\
\text { lemparan }\end{array}$ & $91 \%$ & $\begin{array}{l}\text { Tepat tidaknya Angry Bird mengenai sasaran } \\
\text { bergantung dengan arah lemparannya. Arah } \\
\text { lemparan ini berhubungan dengan sudutnya. Jika } \\
\text { sudut lemparannya tepat maka Angry Bird akan tepat } \\
\text { mengenai sasaran. Cara menentukan sudut lemparan } \\
\text { pada Angry bird ini dengan mengukur sudut antara } \\
\text { garis miring dengan garis horizontal menggunakan } \\
\text { busur derajad. Garis miring ini diperoleh dari } \\
\text { menghubungkan titik-titik/jejak lemparan Angry Bird } \\
\text { sebagai garis lurus. Garis horizontal diperoleh dengan } \\
\text { menggambar garis horizontal dari ketapel sebagai titik } \\
(0,0) \text {. }\end{array}$ \\
\hline \multirow[t]{3}{*}{2} & \multirow{3}{*}{$\begin{array}{l}\text { Menentukan } \\
\text { jarak } \\
\text { horizontal } \\
\text { terjauh }\end{array}$} & \multirow[t]{3}{*}{$87 \%$} & $\begin{array}{l}\text { Untuk menentukan jarak horizontal terjauh yang } \\
\text { ditempuh Angry Bird dengan melempar ke atas } \\
\text { melewati titik sasaran. Jarak horizontal terjauh }\end{array}$ \\
\hline & & & dihitung dari rumus $X_{A}=\frac{v_{0}^{2} \sin 2 \alpha}{g}$. Dengan \\
\hline & & & $\begin{array}{l}\text { mengasumsikan } \mathrm{V}_{0}=100 \mathrm{~m} / \mathrm{s} \text { (Angry Bird ditarik } \\
\text { maksimal). Dari rumus tersebut bisa diperoleh jarak } \\
\text { horizontal terjauh maksimum yang ditempuh Angry } \\
\text { Bird saat } \alpha=45^{0}\end{array}$ \\
\hline \multirow[t]{2}{*}{3} & \multirow{2}{*}{$\begin{array}{l}\text { Menentukan } \\
\text { waktu untuk } \\
\text { mencapai } \\
\text { jarak } \\
\text { horizontal } \\
\text { terjauh }\end{array}$} & \multirow[t]{2}{*}{$84 \%$} & $\begin{array}{l}\text { Dari gambar subtopic nomor } 2 \text { maka waktu untuk } \\
\text { mencapai jarak horizontal terjauh dapat dihitung }\end{array}$ \\
\hline & & & $\begin{array}{l}\text { dengan persamaan } t_{O A}=\frac{2 v_{o y}}{g}=\frac{2 v_{o} \sin \alpha}{g} \text {. Karena } \\
\text { terdapat } 3 \text { gambar, maka waktu dari masing-masing } \\
\text { gambar tersebut dapat diketaui perbedaannya. }\end{array}$ \\
\hline 4 & $\begin{array}{l}\text { Menentukan } \\
\text { tinggi } \\
\text { maksimum }\end{array}$ & $81 \%$ & $\begin{array}{l}\text { Tinggi maksimum ketiga gambar yang dapat ditempuh } \\
\text { Angry Bird dapat dihitung dengan persamaan } \\
y_{H}=\frac{v_{0}^{2} \sin ^{2} \alpha}{2 g}\end{array}$ \\
\hline \multirow[t]{2}{*}{5} & \multirow{2}{*}{$\begin{array}{l}\text { Menentukan } \\
\text { waktu untuk } \\
\text { mencapai } \\
\text { titik tertinggi }\end{array}$} & \multirow[t]{2}{*}{$77 \%$} & $\begin{array}{l}\text { Waktu untuk mencapai titik tertinggi dari ketiga } \\
\text { gambar yang dapat ditempuh Angry Bird dapat }\end{array}$ \\
\hline & & & dihitung dengan persamaan $t_{O H}=\frac{v_{o y}}{g}=\frac{v_{o} \sin \alpha}{g}$ \\
\hline 6 & $\begin{array}{l}\text { Menentukan } \\
\text { persamaan } \\
\text { posisi dan } \\
\text { kecepatan } \\
\text { pada gerak } \\
\text { parabola }\end{array}$ & $74 \%$ & 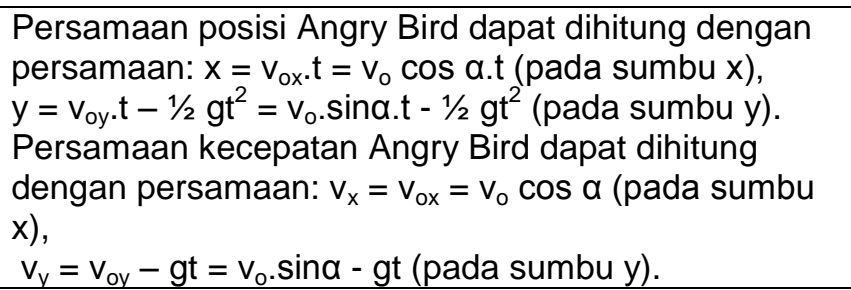 \\
\hline 7 & Menentukan & $71 \%$ & Kecepatan Angry Bird pada saat t sekon ditentukan \\
\hline
\end{tabular}


Vol. 2 No. 4, Oktober 2018;
kecepatan
benda dan
arahnya
oleh persamaan $v=\sqrt{v_{x}^{2}+v_{y}^{2}}$. Saat mencapai titik
pada saat $t$
tertinggi $\mathrm{v}_{\mathrm{y}}=0$
sekon
Arah kecepatan Angry Bird pada saat t sekon
ditentukan oleh persamaan $\tan \alpha=\frac{v_{y}}{v_{x}}$

Tabel 2. Deskripsi Jawaban kuis pada Materi Gerak Prabola

\begin{tabular}{|c|c|c|c|}
\hline Kuis & Subtopik & $\begin{array}{c}\text { Persentase } \\
\text { jawaban (\%) } \\
\text { hasil belajar } \\
\text { kognitif }\end{array}$ & Contoh pernyataan \\
\hline 1 & $\begin{array}{l}\text { Menentukan } \\
\text { besar vektor } \\
\text { satuan dan } \\
\text { posisi }\end{array}$ & $80 \%$ & $\begin{array}{l}\text { 1. Besar vektor A dituliskan } \\
\qquad|O A|=|\vec{r}| \\
|\vec{r}|=\sqrt{3^{2}+4^{2}}=\sqrt{9+16}=\sqrt{25}=5 \text { satuan } \\
\text { 2. Vector posisi } \vec{r} \text { dalam ungkapan vektor satuan } \\
\hat{i} \text { dan } \hat{j} \text { dapat dituliskan sebagai } \vec{r}=x \hat{i}+y \hat{j} \text {. } \\
\text { Karena } \mathrm{x}=18 \mathrm{t} \text { dan } \mathrm{y}=4 \mathrm{t}-5 \mathrm{t}^{2} \text {, maka } \\
\vec{r}=(18 t) \hat{i}+\left(4 \mathrm{t}-5 \mathrm{t}^{2}\right) \hat{j}\end{array}$ \\
\hline 2 & $\begin{array}{l}\text { Menentukan } \\
\text { jarak } \\
\text { horizontal } \\
\text { terjauh }\end{array}$ & $79 \%$ & $\begin{array}{l}\text { Diketahu: } \mathrm{v}_{\mathrm{o}}=10 \mathrm{~m} / \mathrm{s} ; \alpha=37^{0} . \\
X_{A}=\frac{v_{0}^{2} \sin 2 \alpha}{g}=\frac{100.2 \sin 37^{0} \cos 37^{0}}{10} \\
X=20(0,6)(0,8)=9,6 \mathrm{~m} . \\
\text { Jadi, air tersebut akan menyentuh tanah pada jarak } \\
9,6 \mathrm{~m} \text { dari selang }\end{array}$ \\
\hline & $\begin{array}{l}\text { Menentukan } \\
\text { waktu untuk } \\
\text { mencapai } \\
\text { jarak } \\
\text { horizontal } \\
\text { terjauh }\end{array}$ & $69 \%$ & $\begin{array}{l}\text { Ditanyakan : Sudut elevasi agar gerak parabola } \\
\text { dapat mencapai titik terjauh. } \\
\text { Ketika mencapai tanah, } \mathrm{t}=2 \mathrm{v}_{\mathrm{o}} \sin \alpha / \mathrm{g} \text {, sehingga } \\
x=\mathrm{v}_{0} \cos \alpha\left(2 \mathrm{v}_{0} \sin \alpha / \mathrm{g}\right) \\
\mathrm{x}=\mathrm{v}_{\mathrm{o}}^{2} .2 \sin \alpha \cos \alpha / \mathrm{g} \\
\sin 2 \alpha=2 \sin \alpha \cos \alpha \\
\mathrm{x}=\mathrm{v}_{\mathrm{o}}^{2} \sin 2 \alpha / \mathrm{g} \\
\mathrm{v}_{\mathrm{o}} \text { dan } \mathrm{g} \text { konstan } \\
\text { Nilai } X \text { bergantung dari nilai } \alpha \text {. dan akan bernilai } \\
\text { maksimum, jika nilai sin } 2 \alpha \text { maksimum. } \\
\text { Nilai maksimum } \sin 2 \alpha=1 \text { dan itu terjadi pada saat } \\
2 \alpha=90^{\circ} \text { atau } \alpha=45^{\circ} . .<-- \text { TERBUKTI }\end{array}$ \\
\hline \multirow[t]{2}{*}{3} & $\begin{array}{l}\text { Menentukan } \\
\text { tinggi } \\
\text { maksimum }\end{array}$ & $78 \%$ & $\begin{array}{l}\text { Diketahui : } v_{\mathrm{o}}=120 \mathrm{~m} / \mathrm{s}, \theta=30^{\circ} \\
\text { tinggi maksimum: } \\
y_{H}=\frac{v_{0}^{2} \sin ^{2} \alpha}{2 g}=\frac{120^{2}(\sin 30)^{2}}{2 x 10}=\frac{14400(1 / 2)^{2}}{20} 180 \mathrm{~m}\end{array}$ \\
\hline & $\begin{array}{l}\text { Menentukan } \\
\text { waktu untuk } \\
\text { mencapai titik } \\
\text { tertinggi }\end{array}$ & $81 \%$ & $\begin{array}{l}\text { Diketahui : } v_{o}=120 \mathrm{~m} / \mathrm{s}, \alpha=30^{\circ} \\
\text { waktu untuk mencapai titik tertinggi: } \\
t_{\text {maks }}=\frac{v_{o y}}{g}=\frac{v_{o} \sin \alpha}{g}=\frac{120 . \sin 30}{10}=\frac{120 x \frac{1}{2}}{10}=6 \mathrm{~s}\end{array}$ \\
\hline 4 & $\begin{array}{l}\text { Menentukan } \\
\text { persamaan } \\
\text { posisi dan } \\
\text { kecepatan } \\
\text { pada gerak } \\
\text { parabola }\end{array}$ & $65 \%$ & $\begin{array}{l}\text { 1. Data-data yang diketahui pada soal: } \\
v_{0}=60 \mathrm{~m} / \mathrm{s} ; \quad g=10 \mathrm{~m} / \mathrm{s}^{2} \\
t=1 \mathrm{~s} ; \quad \alpha=53^{\circ} \\
\text { Sudut } \alpha=53^{\circ} \text { merupakan sudut segitiga siku- } \\
\text { siku yang bisa digambarkan sebagai berikut: } \\
\text { Sin } 53=4 / 5 \\
\text { Cos } 53=3 / 5 \\
\text { Tan } 53=4 / 3\end{array}$ \\
\hline
\end{tabular}


Gerak horizontal pada gerak parabola merupakan gerak lurus beraturan (GLB), sehingga:

$x=v_{0} \cos \alpha \cdot t$

$=60 \cdot \cos 53^{\circ} \cdot 1$

$=60 \cdot 3 / 5 \cdot 1$

$=36 \mathrm{~m}$

Sedangkan gerak vertikal pada gerak parabola merupakan gerak lurus berubah beraturan (GLBB), sehingga:

$y=v_{0} \sin \alpha-1 / 2 g t^{2}$

$=60 \cdot \sin 53^{\circ}-1 / 2 \cdot 10 \cdot 1^{2}$

$=60 \cdot 4 / 5-5$

$=48-5$

$=43 \mathrm{~m}$

Jadi, posisi peluru pada detik ke-1 adalah $x=36 \mathrm{~m}, y=43 \mathrm{~m}$

2. Kecepatan peluru untuk sumbu $x$ :

$v_{x}=v_{0} \cos \theta=60 \cdot 1 / 2 \sqrt{ } 3=30 \sqrt{ } 3 \mathrm{~m} / \mathrm{s}$

Kecepatan peluru untuk sumbu y:

$v y=v_{0} \sin \theta-g \cdot t=60 \cdot 1 / 2-(10.2 s)$ $=30-20=10 \mathrm{~m} / \mathrm{s}$

Menentukan

benda dan

arahnya pada

saat t sekon
$63 \%$$$
=30-20=10 \mathrm{~m} / \mathrm{s}
$$

Dik : $\mathrm{v}_{\mathrm{o}}=10 \mathrm{~m} / \mathrm{s} ; \mathrm{t}=0,4 \mathrm{~s} ; \theta=37^{\circ}$

Untuk mengetahui kecepatan peluru setelah 3

detik maka kita harus menentukan terlebih dahulu

$v_{x}$ dan $v_{y}$ setelah 3 detik sebagai berikut :

$v_{x}=v_{0 x}($ Ingat bahwa GLB kecepatannya tetap)

$\Rightarrow \mathrm{v}_{\mathrm{x}}=\mathrm{v}_{\mathrm{o}} \cos \theta$

$\Rightarrow \mathrm{v}_{\mathrm{x}}=10 \cos 37^{\circ}$

$\Rightarrow v_{\mathrm{x}}=10(4 / 5)$

$\Rightarrow \mathrm{v}_{\mathrm{x}}=8 \mathrm{~m} / \mathrm{s}$

$v_{y}=v_{o y}-g . t$ (dalam arah vertikal berlaku GLBB)

$\Rightarrow v_{\mathrm{y}}=\mathrm{v}_{\mathrm{o}} \sin \theta-\mathrm{g} . \mathrm{t}$

$\Rightarrow v_{y}=10 \sin 37^{\circ}-10 .(0,4)$

$\Rightarrow v_{\mathrm{y}}=10(3 / 5)-4$

$\Rightarrow \mathrm{v}_{\mathrm{y}}=6-4$

$\Rightarrow v_{\mathrm{y}}=2 \mathrm{~m} / \mathrm{s}$

$\mathrm{v}_{\mathrm{t}}=\sqrt{ }\left(\mathrm{v}_{\mathrm{x}}^{2}+\mathrm{v}_{\mathrm{v}}^{2}\right)$

$\Rightarrow v_{t}=\sqrt{ }\left(8^{2}+2^{2}\right)$

$\Rightarrow v_{\mathrm{t}}=\sqrt{68}$

$\Rightarrow \mathrm{v}_{\mathrm{t}}=2 \sqrt{ } 17 \mathrm{~m} / \mathrm{s}$.

$\tan \theta=\frac{v_{y}}{v_{x}}=\frac{2}{8}=0,25$

$\Theta=\arctan 0,25=14^{\circ}$

Jadi, arah kecepatan peluru setelah $0,4 \mathrm{~s}$ adalah $14^{\circ}$ 
JURNAL PENDIDIKAN: Riset \& Konseptual

Vol. 2 No. 4, Oktober 2018;

Tabel 3. Deskripsi Jawaban pre-test dan post-test pada Materi Gerak Prabola

\begin{tabular}{|c|c|c|c|}
\hline No. & Subtopik & $\begin{array}{c}\text { Persentase } \\
\text { jawaban (\%) } \\
\text { hasil belajar } \\
\text { kognitif }\end{array}$ & Contoh pernyataan \\
\hline 1 & $\begin{array}{l}\text { Menggambarkan } \\
\text { vektor } \\
\text { kecepatan dan } \\
\text { komponennya }\end{array}$ & $93 \%$ & $\begin{array}{l}\text { Karakteristik gerak parabola } \\
\text { 1. Lintasan geraknya berbentuk parabola } \\
\text { 2. Gerak parabola merupakan perpaduan antara } \\
\text { GLB ke arah horizontal (sumbu } x \text { ) dan GLBB ke } \\
\text { arah vertikal (sumbu y). } \\
\text { 3. Gerak vertikal pada gerak parabola tidak } \\
\text { dipengaruhi oleh gerak horizontalnya. } \\
\text { 4. Hanya percepatan gravitasi yang terjadi dalam } \\
\text { gerak parabola } \\
\text { 5. Pada titik tertinggi, kecepatan vertikal benda } \\
\text { bernilai nol. } \\
\text { 6. Kecepatan horizontal gerak parabola tidak } \\
\text { tergantung pada waktu. }\end{array}$ \\
\hline 2 & $\begin{array}{l}\text { Menentukan } \\
\text { jarak horizontal } \\
\text { terjauh }\end{array}$ & $83 \%$ & $\begin{array}{l}\text { Jarak horizontal terjauh dihitung dari rumus } \\
X_{C}=\frac{\nu_{0}^{2} \sin 2 \alpha}{g}\end{array}$ \\
\hline 3 & $\begin{array}{l}\text { Menentukan } \\
\text { waktu untuk } \\
\text { mencapai jarak } \\
\text { terjauh }\end{array}$ & $84 \%$ & $\begin{array}{l}\text { Waktu untuk mencapai jarak horizontal terjauh } \\
\text { dapat dihitung dengan persamaan } \\
t_{A C}=\frac{2 v_{o y}}{g}=\frac{2 v_{o} \sin \alpha}{g} \text {. }\end{array}$ \\
\hline 4 & $\begin{array}{l}\text { Menentukan } \\
\text { tinggi maksimum }\end{array}$ & $88 \%$ & $\begin{array}{l}\text { Tinggi maksimum dapat dihitung dengan } \\
\text { persamaan } y_{H}=\frac{\nu_{0}^{2} \sin ^{2} \alpha}{2 g}\end{array}$ \\
\hline 5 & $\begin{array}{l}\text { Menentukan } \\
\text { waktu untuk } \\
\text { mencapai titik } \\
\text { tertinggi }\end{array}$ & $84 \%$ & $\begin{array}{l}\text { Waktu untuk mencapai titik tertinggi dapat dihitung } \\
\text { dengan persamaan } t_{A B}=\frac{v_{o y}}{g}=\frac{\nu_{o} \sin \alpha}{g}\end{array}$ \\
\hline 6 & $\begin{array}{l}\text { Menentukan } \\
\text { persamaan } \\
\text { posisi dan } \\
\text { kecepatan pada } \\
\text { gerak parabola }\end{array}$ & $90 \%$ & $\begin{array}{l}\text { Menentukan posisi: } \\
\text { Untuk } \mathrm{t}=0 \mathrm{~s} \\
x=v_{0} \cos \alpha \cdot t=0 \mathrm{~m} \\
y=v_{0} \sin \alpha-1 / 2 g t^{2}=0 \mathrm{~m} \\
\text { Untuk } \mathrm{t}=0,25 \mathrm{~s} \\
x=v_{0} \cos \alpha \cdot t=10 \cos 30^{\circ} \cdot 0,25=2,2 \mathrm{~m} \\
y=v_{0} \sin \alpha-1 / 2 g t^{2}=10 \sin 30^{\circ}-1 / 2 \cdot 10 \cdot(0,25)^{2}= \\
0,94 \mathrm{~m} \\
\text { Untuk } \mathrm{t}=0,5 \mathrm{~s} \\
x=v_{0} \cos \alpha \cdot t=10 \cos 30^{\circ} \cdot 0,5=4,3 \mathrm{~m} \\
y=v_{0} \sin \alpha-1 / 2 g t^{2}=10 \sin 30^{\circ}-1 / 2 \cdot 10 \cdot(0,5)^{2}= \\
1,25 \mathrm{~m} \\
\text { Untuk } \mathrm{t}=0,75 \mathrm{~s} \\
x=v_{0} \cos \alpha \cdot t=10 \cos 30^{\circ} \cdot 0,75=6,5 \mathrm{~m} \\
y=v_{0} \sin \alpha-1 / 2 g t^{2}=10 \sin 30^{\circ}-1 / 2 \cdot 10 \cdot(0,75)^{2}= \\
0,94 \mathrm{~m}\end{array}$ \\
\hline
\end{tabular}


Untuk $\mathrm{t}=1 \mathrm{~s}$

$x=v_{0} \cos \alpha \cdot t=10 \cos 30^{\circ} .1=8,6 \mathrm{~m}$

$y=v_{0} \sin \alpha-1 / 2 g t^{2}=10 \sin 30^{\circ}-1 / 2 \cdot 10 \cdot(1)^{2}=0 \mathrm{~m}$

Menentukan kecepatan:

Untuk $\mathrm{t}=0 \mathrm{~s}$

$\mathrm{v}_{\mathrm{x}}=\mathrm{v}_{\mathrm{o}} \cos \theta=10 \cos 30^{\circ}=8,66 \mathrm{~m} / \mathrm{s}$

$v_{y}=v_{\text {oy }}-g . t=10 \sin 30^{\circ}-10.0=5 \mathrm{~m} / \mathrm{s}$

Untuk $\mathrm{t}=0,25 \mathrm{~s}$

$\mathrm{v}_{\mathrm{x}}=\mathrm{v}_{\mathrm{o}} \cos \theta=10 \cos 30^{\circ}=8,66 \mathrm{~m} / \mathrm{s}$

$v_{y}=v_{\text {oy }}-g . t=10 \sin 30^{\circ}-10 \cdot 0,25=2,5 \mathrm{~m} / \mathrm{s}$

Untuk $\mathrm{t}=0,5 \mathrm{~s}$

$\mathrm{v}_{\mathrm{x}}=\mathrm{v}_{\mathrm{o}} \cos \theta=10 \cos 30^{\circ}=8,66 \mathrm{~m} / \mathrm{s}$

$v_{y}=v_{o y}-g . t=10 \sin 30^{\circ}-10.0,5=0 \mathrm{~m} / \mathrm{s}$

Untuk $\mathrm{t}=0,75 \mathrm{~s}$

$\mathrm{v}_{\mathrm{x}}=\mathrm{v}_{\mathrm{o}} \cos \theta=10 \cos 30^{\circ}=8,66 \mathrm{~m} / \mathrm{s}$

$v_{y}=v_{\text {oy }}-g . t=10 \sin 30^{\circ}-10.0,75=-2,5 \mathrm{~m} / \mathrm{s}$

Untuk $\mathrm{t}=1 \mathrm{~s}$

$\mathrm{v}_{\mathrm{x}}=\mathrm{v}_{\mathrm{o}} \cos \theta=10 \cos 30^{\circ}=8,66 \mathrm{~m} / \mathrm{s}$

$v_{y}=v_{\text {oy }}-g . t=10 \sin 30^{\circ}-10.1=-5 \mathrm{~m} / \mathrm{s}$

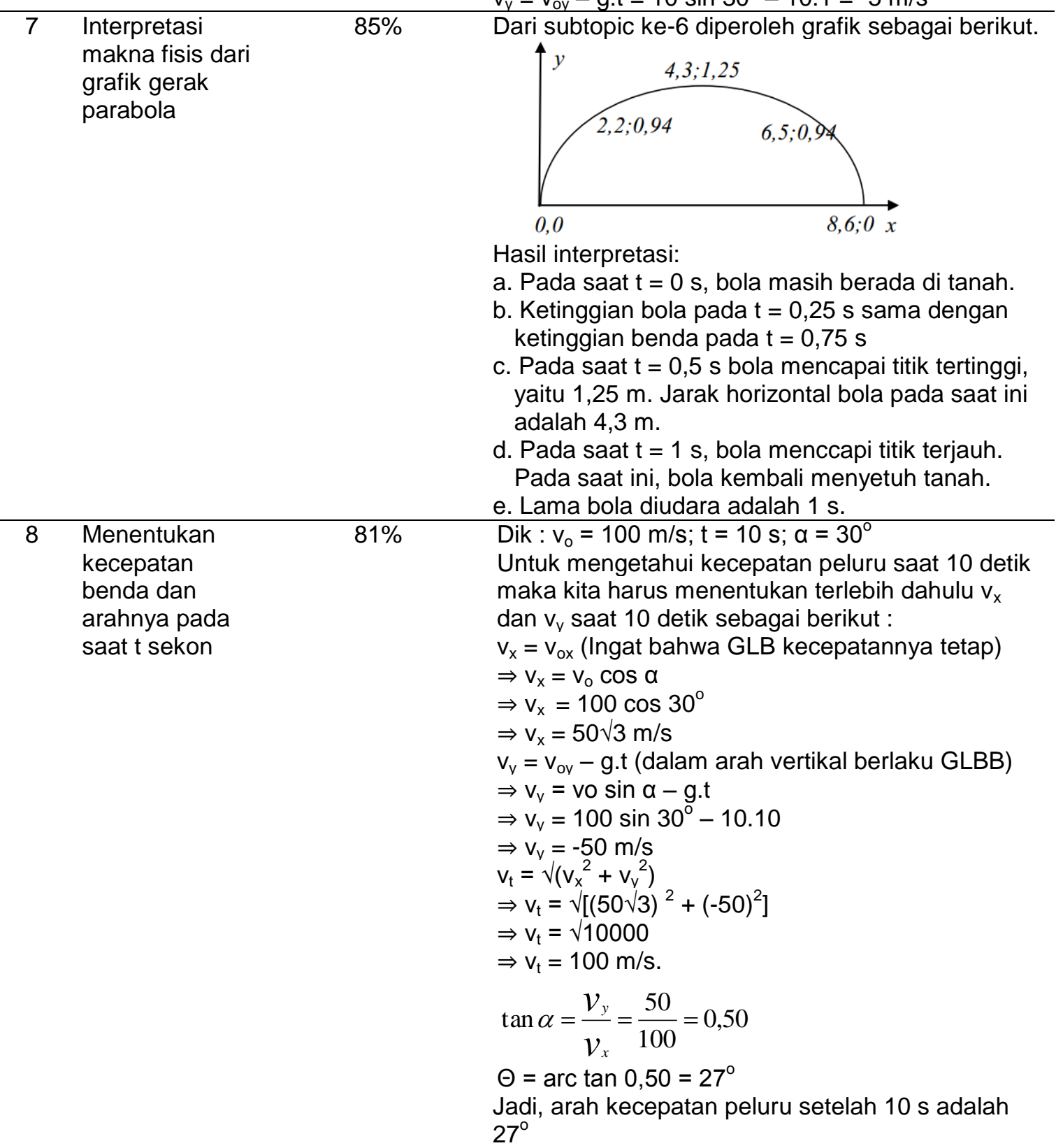


Tabel 4. Rata-Rata Hasil Belajar Kognitif Fisika pada Setiap Sub-Topik Materi Gerak Parabola

\begin{tabular}{lccc}
\hline Sub-Materi Gerak Parabola & $\begin{array}{c}\text { Pre-Test } \\
(\%)\end{array}$ & $\begin{array}{c}\text { Post-Test } \\
(\%)\end{array}$ & $\begin{array}{c}\text { Perubahan Hasil } \\
\text { Belajar Kognitif Fisika } \\
(\%)\end{array}$ \\
\hline $\begin{array}{l}\text { Menggambarkan vektor } \\
\text { kecepatan dan komponennya }\end{array}$ & 36 & 93 & 63 \\
\hline $\begin{array}{l}\text { Menentukan jarak horizontal } \\
\text { terjauh }\end{array}$ & 33 & 83 & 50 \\
\hline $\begin{array}{l}\text { Menentukan waktu untuk } \\
\text { mencapai jarak terjauh }\end{array}$ & 32 & 84 & 52 \\
\hline $\begin{array}{l}\text { Menentukan tinggi maksimum } \\
\text { Menentukan waktu untuk } \\
\text { mencapai titik tertingi }\end{array}$ & 30 & 88 & 58 \\
\hline $\begin{array}{l}\text { Menentukan persamaan posisi } \\
\text { dan kecepatan pada gerak } \\
\text { parabola }\end{array}$ & 25 & 84 & 59 \\
\hline $\begin{array}{l}\text { Interpretasi makna fisis dari grafik } \\
\text { gerak parabola }\end{array}$ & 27 & 90 & 65 \\
\hline $\begin{array}{l}\text { Menentukan kecepatan benda } \\
\text { dan arahnya pada saat t sekon }\end{array}$ & 23 & 81 & 57 \\
\hline
\end{tabular}

Tabel 5. Deskripsi Hasil Belajar Kognitif fisika siswa dari Pre-Test ke Post-Test

\begin{tabular}{lcc}
\hline $\begin{array}{c}\text { Unsur-Unsur } \\
\text { Statistik }\end{array}$ & Pre-Test & Post-Test \\
\hline \multicolumn{1}{c}{$\mathrm{N}$} & 33 & 33 \\
\hline $\bar{x}$ & 60 & 195 \\
\hline$X_{\text {min }}$ & 33 & 165 \\
\hline$X_{\text {maks }}$ & 88 & 215 \\
\hline $\bar{X}_{\text {Post }}-\bar{X}_{\text {Pre }}$ & 127 & \\
\hline Sign Uji-t post-pre & 0,00 & \\
\hline
\end{tabular}

\section{PEMBAHASAN}

Tabel 1 menunjukkan bahwa hasil belajar kognitif fisika yang diperoleh melalui percobaan game Angry Bird telah baik. Hasil belajar kognitif fisika materi gerak parabola telah baik ditunjukkan dari rata-rata jawaban siswa yang ada pada LKS adalah sebesar $80,7 \%$. Dengan demikian, melalui pembelajaran dengan game Angry Bird ini hasil belajar kognitif fisika siswa yang diperoleh pada konsep gerak parabola adalah baik.

Tabel 2 menunjukkan bahwa hasil belajar kognitif fisika yang diperoleh melalui kuis antara $63 \%-80 \%$. Siswa diberikan kuis pada akhir kegiatan pembelajaran untuk menguji apakah mereka benar-benar memahami konsep yang diperoleh dari pembelajaran untuk diterapkan pada masalah yang baru. Berdasarkan hasil analisis kuis diperoleh rata-rata nilai hasil belajar kognitif fisika adalah 73,57\%. Berarti siswa telah memahami konsep yang berhubungan dengan gerak parabola. Dengan demikian, setelah melalui pembelajaran dengan game Angry Bird ini hasil belajar kognitif fisika mengalami peningkatan.

Secara kuantitatif, hasil belajar kognitif fisika dapat diamati dari setiap subtopik materi gerak parabola pada pre-test dan post-test. Perubahan hasil belajar kognitif fisika siswa setiap subtopik materi gerak parabola ditunjukkan pada Tabel 4. 
Vol. 2 No. 4, Oktober 2018;

Berdasarkan Tabel 5. menunjukkan bahwa terdapat perubahan skor rata-rata hasil belajar kognitif fisika siswa. Perubahan skor rata-rata dari pre-test ke post-test mengalami kenaikan sebesar 127. Kenaikan skor rata-rata tersebut menunjukkan bahwa hasil belajar kognitif fisika siswa mengalami perubahan menjadi lebih baik.

Berdasarkan hasil analisis uji-t berpasangan diperoleh $0,00<0,05$ sehingga $H_{o}$ ditolak sehingga $H_{a}$ diterima. Hasil yang diperoleh menunjukkan bahwa terdapat perbedaan yang signifikan antara hasil belajar kognitif fisika siswa sebelum dan setelah pembelajaran.

\section{KESIMPULAN}

Terdapat pengaruh penerapan game Angry Bird terhadap hasil belajar kognitif fisika siswa. Hal ini ditunjukan melalui hasil kuis diperoleh skor rata-rata hasil belajar kognitif fisika siswa sebesar $73,57 \%$. Selain itu, dari hasil LKS diperoleh skor rata-rata hasil belajar kognitif fisika siswa sebesar 80,7 \%. Dengan demikian, setelah menerapkan game Angry Bird ini siswa dapat belajar konsep gerak parabola dengan baik.

Hasil belajar kognitif fisika siswa mengalami perubahan setelah penerapan game Angry Bird. Perubahan ini ditunjukkan melalui perubahan skor rata-rata hasil belajar kognitif fisika siswa pada post-test yang lebih baik daripada pre-test. Hasil ini juga di dukung oleh hasil analisis uji-t berpasangan yang menunjukkan bahwa terdaat perbedaan antara skor rata-rata hasil belajar kognitif fisika siswa pada pre-test dan pos-test.

\section{SARAN}

Perlu menciptakan suasana yang menarik dalam fase mengorientasi siswa pada masalah dengan menggunakan kegiatan bervariasi yang didukung dengan video dan animasi sehingga siswa dapat dengan mudah mengamati orientasi permasalahan awal yang diberikan. Bimbingan yang inten perlu dilakukan ketika siswa melakukan eksperimen dan diskusi kelompok agar tidak terjadi kesalahan dalam prosedur percobaan yang dilakukan. Rancangan percobaan yang akan diberikan ke siswa sebaiknya diuji cobakan terlebih dahulu agar kegiatan eksperimen yang akan dilakukan di kelas dapat memperoleh data yang diinginkan. Perlu adanya metode yang tepat untuk diterapkan ketika siswa melakukan kegiatan eksperimen dan menjawab pertanyaan diskusi agar alokasi waktu yang digunakan pada kegiatan ini tidak terlalu banyak. Perlu adanya metode yang tepat untuk diterapkan ketika siswa melakukan presentasi agar siswa lain dapat bertanya dan mengemukakan pendapat.

\section{DAFTAR RUJUKAN}

Allain R. 2010. The physics of Angry Birds (www.wired.com/wiredscience/2010/10/ physics-of-angry-bird), diunduh 5 Mei 2017

Allain R. 2010. Does the Angry Blue Bird multiply its mass? (www.wired.com/wired science/2010/10/does-the-angry-blue-bird-multiply-its-mass), diunduh 5 Mei 2017

Allain R. 2011. Physics of the yellow Angry Bird (www.wired.com/wiredscience /2011/11/ physics-of-the-yellow-angry-bird), diunduh 5 Mei 2017

Allain. 2011. How does the green Angry Bird Work? (www.wired.com/wiredscience/ 2011/04/how-does-the-green-angry-bird-work), diunduh 5 Mei 2017

Dani, M., 2008. Pembelajaran Interaktif dan Atraktif Berbasis Game dan Animasi untuk Pendidikan Dasar dan Menengah di Indonesia. Jakarta, e-Indonesia Initiative 2008 (ell2008).

Deasyana, dkk. 2013. Game Angry Bird dan Program Tracker sebagai Media Pembelajaran Fisika pada Topik Gerak Parabola. Salatiga: Prosiding Seminar Nasional Sains dan Pendidikan Sains VIII, FMIPA UKSW 
Vol. 2 No. 4, Oktober 2018;

IGN. 2009. Angry Birds review, IGN.com. (http://uk.ign.com/articles/2010/02/19/angrybirds-review-2), diunduh 5 Mei 2017

Maclsaac D. 2011. Angry Birds: the physics phenomenon Phys. Teach. 49399

Rodrigues, M. \& Carvalho, P. S., 2013. Teaching physics with Angry Birds: exploring the kinematics and dynamics of the game. Physics Education, p. 431. 